\title{
References
}

BOOTH, A.H. 1957 Observations on the natural history of the olive colobus. Proc. Zool. Soc. Lond., 129, 3. Ghana Government. Wildlife Conservation Regulations 1971 International Union for Conservation of Nature. 1968 Red Data Book vol. 1, Mammals. JEFFREY, S.M. 1970a Ghana's forest wildlife in danger. Oryx X: 4.

JEFFREY, S.M. 1970b Elephants on the farm. Oryx X: 5.

JEFFREY, S.M. in press. Notes on the mammals of the dry high forest of Ghana. Bull. IFAN ser. A.

\section{Can the Animal Technician Help?}

\section{Marvin L. Jones}

In Oryx, June 1974, W. R. Kingston proposed that twenty-five pairs of golden lion marmosets Leontopithecus rosalia be placed in a laboratory-type setting for the purpose of increasing captive reproduction and possibly acting as a bank to save the species. This proposal suggests that Mr Kingston' is not familiar with the captive husbandry of the species.

I have been collecting data on captive animals for over thirty years and have examined the records of most zoos in Europe and North America, as well as the Far East and Australia. Since mid-1970 I have been serving as the studbook keeper for the golden lion marmoset for the American Association of Zoological Parks and Aquariums (AAZPA), and in early 1973 a studbook was issued and noticed in Oryx. (As a matter of interest, I did not receive a single request for a copy as a result of this note.)

At the time information was being collected for the studbook it was decided not to request data on animals that had been in collection prior to 1960 , unless they or their descendants were living as of January 11960 . Before that records systems in many collections were not well maintained, and also this was felt to be a good base-line year from which to begin. But I have now gone over all my data since the end of World War II, beginning January 1 1946; much of this has not been published.

The pet trade aside, examination of zoo records shows that 30 United States collections, including one laboratory, imported 168 golden lion marmosets from 1946 to 1968. Eighteen of these succeeded in breeding some 231 specimens as of mid-1974, and as of 1 September 1974 no fewer than 72 were still living. Even more important, 23 of the 72 represented second-generation breeding. In 18 of these both parents were captive-bred, and in 14 one parent was captive-bred. However, the 26 European collections that imported 153 animals in the same time frame bred only 30 , and bred not a single one to the second generation. Only two of these animals are now living; one is a wild import, one a captive-bred specimen.

The one laboratory that imported the species, the Houston Dental Science Institute of Dr Barnet Levy, certainly cannot be held up as a model of what the laboratory can do. Thirteen (6/7) specimens were imported in 1963. One lived ten years, but not a single birth was registered in this laboratory where the animals were kept in much the manner suggested by Mr Kingston, and for many years fed on the diet described by Dr Levy. On the other hand, the 
San Diego Zoo which imported 3/7 animals in the same year, and still had one animal left from a 1959 importation, did breed the species. Three were bred in 1964, five in 1965, and four in 1966, not a zero as Mr Kingston suggests. Admittedly, the San Diego colony has undergone a decline in recent years and now has only four males, two on breeding loans to other zoos. The remaining two males have been offered to Dr Coimbra-Filho for the breeding project in Brazil.

After examining the breeding records of all the zoos that have had success with the species, it is obvious that, unlike other marmosets, the golden lion does not breed well on a continuing basis in a colony situation. In fact, presence of siblings has been shown to impair further breeding by adult animals. As the Levy experience shows, animals kept in one room may not breed at all. The two zoos currently having the best success, Oklahoma City and Washington DC, have found that breeding is best when the marmosets are separated in pairs. These two zoos now have 34 specimens, all but four captive-bred, and 17 are either pure or partial second generation. These zoos show promise of being able to maintain a viable population for the years ahead. How they keep and maintain their animals should be used as the model for the future, rather than the procedures of a non-productive laboratory situation.

The author is at the San Diego Wild Animal Park, P.O. Box 551 San Diego, California 92112 USA

\section{STUDBOOK NEWS}

\section{Carnivores}

The Columbia Zoological Park, Columbia, South Carolina, is accumulating data for studbooks on the brown hyaena Hyaena brunnea and three races of leopard Panthera pardus: P. p. japonensis from North China, $P$. $p$. orientalis from the Amur region, and $P$. p. saxicolor from Afghanistan and Iran.

\section{Snow Leopards}

The studbook for snow leopards is being kept by the Lincoln Park Zoo, Chicago.

\section{Przewalski Horse}

According to the latest issue of this studbook, there were 219 Przewalski horses in captivity on January 1, 1974, an increase of 13 during the year. Thirty foals were born at 14 zoos during 1973 .

\section{African Wild Ass}

On January 1, 1973, five zoos and the Hai-Bar reserve in Israel had between them 44 African wild asses Equus asinus, of which twelve at Hai Bar and seven at Basel are of the Somali race somalicus (see page 74). The rest are of indeterminate subspecies, originating from the Munich Zoo, which still has six. Catskill, New York, has the largest captive herd, 16.

\section{Asiatic Wild Ass}

The latest edition of this studbook shows 174 kulans Equus hemionus kulan in 52 zoos on January 1,1973 . On the same date there were at least 96 and perhaps 108 onagers $E$. h. onager in 29 (perhaps 34) zoos, and ten kiangs $E . h$. kiang in two zoos (Kaunas and Riga). Also seven zoos had nine hybrids. The zoo with the largest number of kulans was Askania Nova with 20, while Catskill (13) and Hamburg (11) headed the list for onagers. Hai Bar reserve in Israel had eight onagers and three kulans not included in the above figures.

\footnotetext{
Japanese Serow

Seventy-five Japanese serows Capricornis crispus, a 'goat-antelope' type of ungulate, are currently in captivity, according to the Japanese serow studbook keeper, Atsushi Komori of the Tama Zoological Park, Hodokubo, Hino, Japan. All except two, which are in one Chinese zoo, are located in 13 Japanese zoos or other institutions.
} 